\title{
O dia em que a morte morrerá
}

\author{
The day death will die
}

*Cinara Nahra

Resumo: O objetivo do presente artigo é mostrar que os temas do envelhecimento populacional e da superpopulação no planeta colocamse como dois dos maiores desafios éticos e de políticas públicas no século XXI em todo o mundo. Apresentamos, aqui, o conceito de imortalidade, trazido para a cena filosófica por John Harris, e mostramos que se for mantido o aumento constante na expectativa de vida que tem sido observado nos últimos 160 anos, na razão de três meses por ano, podemos esperar que, daqui a 40 mil anos, a expectativa de vida seja de aproximadamente 10 mil anos, o que poderíamos caracterizar como imortalidade, levando-se em conta a expectativa de vida que temos hoje. Discutimos, então, se a imortalidade é ou não desejável e mostraremos que o argumento de Hans Jonas de que a imortalidade necessariamente levará ao fim da reprodução não se sustenta.

Palavras-Chave: envelhecimento populacional, expectativa de vida, imortalidade, políticas públicas.

\begin{abstract}
The aim of this article is to show that population ageing and overpopulation are two of the greatest challenges in ethics and public policies for mankind in the XXI century. I introduce the concept of immortality, brought to the philosophical scene by John Harris, and I show that if life expectancy continues to increase at the same rate of the last 160 years it can be expected that in 40 thousand years from now life expectancy will reach approximately 10 thousand years, which will be considered immortality if we consider life expectancy in the beginning of the $21^{\text {st }}$ century. I will also discuss the desirability of immortality and I will show that Hans Jonas's argument that immortality will necessarily lead to the end of reproduction does not hold.
\end{abstract}

Keywords: immortality, life expectancy, population ageing, public policies.

* Professora do PPG em Filosofia da UFRN, Natal, Brasil. Pesquisadora do CNPq. Endereço Postal: Programa de Pós-Graduação em Filosofia - sala 706, Centro de Ciências Humanas, Letras e Artes (CCHLA), Campus Universitário - Lagoa Nova - Natal/RN CEP 59076-970. <cinaranahra@hotmail.com>.

\begin{tabular}{|l|l|l|l|l|l|}
\hline Veritas & Porto Alegre & v. 58 & n. 1 & jan./abr. 2013 & p. 87-98 \\
\hline
\end{tabular}




\section{A superpopulação no planeta Terra}

Ocorreu, em algum momento durante o ano de 2011, o nascimento do bebê que fez com que a população humana na terra atingisse o sétimo bilhão. Se, por um lado, temos motivos para comemorar o sucesso reprodutivo da nossa espécie, por outro, há motivos de sobra para preocupação. Segundo o Population Reference Bureau, ${ }^{1}$ em algum ponto por volta de 1800 , a população humana atingiu seu primeiro bilhão. A situação, agora, é muito diferente e a população humana aumenta na taxa de um bilhão de indivíduos a cada 12 anos. Enquanto o século vinte começa com uma população humana em torno de 1.6 bilhões de indivíduos, ele termina com uma população humana em torno de seis bilhões. A previsão é de que seja atingido o oitavo bilhão em 2024.

Mas quais os problemas causados por uma população tão grande? Para John Guillebaud, ${ }^{2}$ o fato de que a população mundial exceda, agora, os 6,7 bilhões e o fato de que o consumo humano de combustível fóssil, água, grãos, peixe e florestas exceda a oferta estão conectados. Para ele, o aumento anual na população, que é de cerca de 79 milhões de pessoas, significa que a cada semana temos um incremento de aproximadamente 1,5 milhões de pessoas que necessitam de comida e moradia. Esse número, compara Guillebaud, corresponde a uma nova grande cidade a cada semana, o que, entre outras coisas, destrói habitat de vida selvagem, aumenta o consumo de combustível fóssil e aumenta as emissões de gases poluidores.

O diagnóstico parece muito claro: se a população mundial continuar a aumentar no ritmo que vem aumentando, os problemas ambientais causados por este aumento vão se agravar consideravelmente. A solução para o problema parece ser elaborar políticas públicas para o século XXI que estimulem a estabilização populacional. Entretanto, há modos de reduzir o crescimento populacional que são claramente insustentáveis do ponto de vista ético, a saber, qualquer proposta de esterilização voluntária de mulheres ou homens e qualquer proposta proibicionista no sentido da criação de leis que tornem ilegal a concepção acima de um determinado limite. Entre as principais razões para que estas medidas sejam consideradas imorais está o fato de que elas afetam diretamente a chamada "liberdade reprodutiva" que é a liberdade que cada indivíduo tem de escolher se e como vai se reproduzir. Restringir esta liberdade

1 POPULATION REFERENCE BUREAU 2010 world population data sheet. Disponível em: <http://www.prb.org/Publications/Datasheets/2010/2010wpds>.

2 "Population growth and climate change" (editorial), British Medical Journal BMJ, p. 337-576 doi, 2008. 
significa restringir uma liberdade fundamental do ser humano e, em última instância, atacar sua autonomia.

Mas se as políticas públicas que promovem a estabilidade populacional são absolutamente necessárias para que o meio ambiente não seja seriamente comprometido pelo crescimento populacional desmedido, e ao mesmo tempo ações como as citadas não passam pelo critério ético, o que fazer? O desafio torna-se ainda maior quando se sabe que a população, especialmente em alguns países mais desenvolvidos, envelhece.

\section{O envelhecimento e o aumento da expectativa de vida da população}

Ha vários estudos sendo feitos sobre como desacelerar o processo de envelhecimento. Kirkwood ${ }^{3}$ afirma que há alguns equívocos na compreensão do processo de envelhecimento. O mais comum destes equívocos é conceber que envelhecemos porque somos programados para morrer a fim de abrir caminho para a próxima geração. Segundo Kirkwood, este fatalismo é contradito pela existência de organismos que não apresentam deterioração intrínseca, como anêmonas marinhas que são espécies que não mostram nenhum sinal de envelhecimento. Há também várias espécies de peixes e tartarugas gigantes que vivem consideravelmente mais do que nós e que envelhecem muito mais lentamente. Para Tom, nós não somos programados com alguma inevitável data de vencimento, ao contrário, nós somos programados não para morrer, mas para sobreviver. Para ele, o envelhecimento chega através da acumulação gradual de defeitos irreparáveis nas nossas células e tecidos que se dão à medida que vivemos, não como o resultado de um mecanismo ativo para a morte e a destruição. Seu veredito é que se for possível descobrir a natureza destes defeitos, teríamos a esperança de controlar este processo.

Tom não esta sozinho. Larry Temkin ${ }^{4}$ cita o geneticista Aubrey de Grey, diretor científico da Fundação Matusalém, que afirma que, em um dos projetos que ele trabalha, o SENS (Strategies for Engineered Negligible Senescence), há um plano detalhado para reparar todos os tipos de dano molecular e celular que nos acontece ao longo dos anos e cada método para fazer isto ou já está funcionando em uma forma preliminar (clinical trials) ou está baseado em tecnologias que já existem e precisam ser combinadas. Isto significa que todas as partes do projeto

KIRKWOOD, Tom. The End of Age. London: Profile Books, 2001.

4 TEMKIN, Larry. "Is living longer living better?", The Journal of Applied Philosophy, 25(3), 2008, p. 193-210. 
devem estar funcionando em ratos em apenas 10 anos e, em 20 anos, já deveriam estar funcionando em humanos.

A pesquisa na área do envelhecimento e seus mecanismos está progredindo e resultados importantes têm sido obtidos no início do século XXI. Em 2009, uma equipe de pesquisadores ganhou o premio Nobel em medicina e fisiologia por seus estudos sobre Telômaros, ${ }^{5}$ que parecem cumprir um papel essencial no processo de envelhecimento. Há também promissores estudos vindos de organismos mais simples, como uma espécie de "mãe d'água", as Turritopsis que, segundo o autor do estudo, rejuvenesceram, passando de medusa a pólipos, tendo isto sido observado 10 vezes, o que é o mais numeroso número de tais ciclos. ${ }^{6}$

Mas o que, então, o futuro reserva-nos? Não há dúvida que a maior realização de todas as possíveis realizações, aquela que provocaria a mais radical mudança na natureza humana em toda História, seria os seres humanos tornarem-se, um dia, imortais. A nossa transformação em seres verdadeiramente imortais, sendo capazes de viver para sempre, como os deuses da mitologia grega, é algo que talvez não sejamos capazes de atingir. Entretanto, a possibilidade de que os futuros membros da nossa espécie vivam cada vez mais é muito alta. Se nós não vivermos para sempre, mas se as pessoas constantemente atingirem idades de milhares e milhares de anos, estas pessoas poderiam ser consideradas imortais comparativamente a nós. A longevidade sadia é já uma realidade nos países mais desenvolvidos. Pessoas vivendo mais e com mais saúde é algo que já vem acontecendo e deveria ser aplaudido como sendo uma das principais realizações de nossa civilização.

Se olharmos para as estatísticas no Brasil, ${ }^{7}$ os dados do IBGE mostram que a expectativa média de vida no Brasil no começo do século XX, mais precisamente em 1919, era de 34 anos, enquanto estas figuras subiram para 67 anos (quase dobraram) em 1991 e foram para 72 anos em 2007. Do começo para o fim do século XX, a expectativa de vida foi dobrada no Brasil. Observe que se fosse possível manter estes números nos próximos quatro séculos, isto é, se a expectativa de vida fosse dobrada

5 Os pesquisadores que ganharam o prêmio Nobel de fisiologia e medicina, em 2009, foram Elizabeth H. Blackburn, da Universidade da Califórnia, Carol W. Greider, da Escola Médica da Universidade Johns Hopkins, e Jack W. Szostak, da Escola Médica de Harvard e do Instituto Médico Howard Hughes. Para uma visão global dos seus estudos e dos estudos com Telômaros e telomerase ver BLACKBURN, Elizabeth, GREIDER, Carol e SZOSTAK, Jack "The path from maize, Tetrahymena and yeast to human cancer and aging“, Nature Medicine, 12(10), 2006, p. vii-xii.

6 KUBOTA, Shin. "Repeating rejuvenation in Turritopsis, an immortal hydrozoan (Cnidaria, Hydrozoa)“, Biogeography, 13 (2011), p.101-103.

7 IBGE Estatísticas do Século XX, Rio de Janeiro (2006). Disponível em: < http://www. ibge.gov.br/seculoxx/seculoxx.pdf>. 
a cada século nos próximos quatro séculos, a expectativa de vida, ao fim do século XXI, seria de 140 anos e, ao final do século XXIV, seria de 1120 anos, isto é, pelo ano 2400, as pessoas poderiam esperar viver em média 1000 anos. Este é obviamente um raciocínio hipotético e não há nenhuma indicação de que seja razoável esperar que as taxas, que foram válidas para o século XX, também serão válidas para os próximos séculos, mas mesmo assim é razoável pensar que a expectativa de vida continuará a crescer a um ponto tal que as pessoas estarão vivendo por tanto tempo que, para efeitos práticos, e especialmente comparando a idade média que vivemos hoje, elas seriam consideradas imortais.

O aumento na expectativa de vida da população é um padrão constante. A expectativa de vida no mundo mais que duplicou nos últimos dois séculos, ${ }^{8}$ passando de aproximadamente 25 anos para aproximadamente 65 anos para homens e 70 anos para mulheres, e de acordo com Oepen: ${ }^{9}$

A expectativa de vida feminina nos países recordistas subiu nos últimos 160 anos em um ritmo permanente de quase três meses por ano. Em 1840 quem tinha maior expectativa de vida eram as mulheres suecas, que viviam em média um pouco mais de 45 anos. Entre as nações, hoje, a maior expectativa de vida - quase 85 anos - é das mulheres japonesas. $O$ aumento de quatro décadas em 16 décadas na expectativa de vida é tão extraordinariamente linear que esta talvez seja a maior regularidade em comportamento de massa já observada. O recorde na expectativa de vida também aumentou linearmente para os homens, embora mais vagarosamente. Por 160 anos as melhores performances em expectativa de vida tem constantemente aumentado um quarto de ano a cada ano, algo absolutamente extraordinário.

Oepen e Vaupel sustentam que centenários podem tornar-se lugar comum ainda no tempo de vida das pessoas que hoje estão vivas. Entretanto, eles também afirmam que isto está ainda muito longe da eternidade e modestos incrementos anuais na expectativa de vida nunca levarão à imortalidade. Mas seria mesmo o caso que modestos incrementos anuais na expectativa de vida não levariam a imortalidade?

\section{O dia em que a morte morrerá}

Richard Dawkins ${ }^{10}$ propôs a seguinte experiência de pensamento: ele pede-nos para imaginar uma mulher contemporânea segurando a mão

8 RILEY, J. Rising Life Expectancy: A Global History. Cambridge: Cambridge Univ. Press, Cambridge, 2001.

9 OEPPEN, J.; VAUPEL, J. "Broken Limits to Life Expectancy“, Science, 296 (2002), p. 1029-1031.

10 DAWKINS, R. "Gaps in The Mind". In: SINGER, P.; CAVALIERI, P. The Great Ape Project. New York: St Martin's Griffin, 1993, p. 81-87. 
de sua mãe na costa africana. Sua mãe segura a mão de sua mãe e assim por diante. Cada mãe que entra na cadeia mantém-se aproximadamente um metro a parte da outra. Após aproximadamente trezentas milhas, esta cadeia imaginária atingiria o primata ancestral. Em outra cadeia, nosso ancestral primata, com sua outra mão, segura a mão da sua outra filha que, por sua vez, segura a mão de sua filha e assim por diante. Ao final desta cadeia, duas fêmeas contemporâneas estarão frente a frente e elas serão um humano moderno e um chimpanzé moderno, um ser humano e um animal. Aqui, peço permissão a Dawkins para propor uma outra experiência de pensamento, imaginando uma cadeia em direção ao futuro. Vamos usar as figuras apresentadas por Oepen, de que o melhor desempenho em termos de expectativa de vida cresceu constantemente um quarto de ano a cada ano, fazendo uma projeção para o futuro, considerando especialmente a regularidade deste aumento particularmente na expectativa de vida feminina em países recordistas. Se a expectativa de vida aumenta três meses ao ano, aumentará 15 meses em cinco anos e 60 meses em 20 anos. Assim, a cada 20 anos, nós teríamos um aumento de cinco anos na expectativa de vida da população feminina. Imaginemos, então, uma fêmea humana moderna de 20 anos de idade parindo duas filhas ao mesmo tempo, e morrendo no parto, e imaginemos que, a cada 20 anos, a partir deste dia cada uma das suas filhas, sucessivamente através das gerações, dará a luz a um bebê do sexo feminino. Enquanto na linha A aquelas filhas viverão aproximadamente o mesmo tempo que nós vivemos agora, cada filha na linha B viverá cinco anos mais que sua mãe. Em 40.000 anos a partir de agora, nós teremos uma mãe que viverá 10.020 anos dando a luz a um bebê que viverá 10.025 anos enquanto na cadeia $\mathrm{A}$ teremos uma mãe que viverá (com sorte) aproximadamente 90 anos dando a luz a um bebê que irá viver, provavelmente, tanto quanto sua mãe. ${ }^{11}$ No fim da cadeia, teremos, para todos os propósitos práticos, olhando face a face, uma semideusa e uma mortal.

A partir deste exemplo, podemos constatar o quanto pequenos aumentos na expectativa de vida podem levar a um grande aumento de longevidade a longuíssimo prazo, o que, na prática, comparando com a idade que as pessoas atingem hoje, nos levaria a considerá-las imortais. Os 40 mil anos a partir de hoje, previstos em nossa experiência de pensamento, correspondem a somente um quinto do tempo total estimado no qual os homo sapiens estiveram na face da terra até hoje (200 mil anos), o que é um tempo muito pequeno na escala cosmológica.

11 Se começarmos nossa cadeia considerando a maior expectativa de vida hoje, que é de 85 anos, no Japão, em 40.000 anos a partir de agora, considerando o aumento de cinco anos, a cada 20 anos, a expectativa de vida dos bebês será de 10.085 anos. 
Teríamos nós, entretanto, todo este tempo? Não se tornaria o planeta Terra antes disto um lugar inóspito? Através de estudos de radiometria, nós podemos calcular que a idade da terra é de aproximadamente 4,5 bilhões de anos. Estudos do astrônomo britânico Robert Smith ${ }^{12}$ estimam que a Terra existirá ainda por aproximadamente 7,6 bilhões de anos, apesar do fato que, segundo ele, em um bilhão de anos, a temperatura na superfície da Terra atingirá centenas de graus Celsius, por causa da expansão solar, e toda água evaporará, tornando impossível a existência de vida humana. Se colocarmos as coisas em perspectiva e se levarmos em consideração todos estes números, veremos que os homo-sapiens ainda têm um longo caminho a percorrer e evoluir neste planeta. Se as condições favoráveis para a existência de vida, aqui, na Terra, continuarem por outro bilhão de anos, então, o que pode ser ainda alcançado em termos de melhoria para a vida de cada indivíduo e melhoramento da espécie é ainda inimaginável. Se a expectativa de vida continuar a aumentar nas taxas que vem aumentando desde a metade do século XIX, um dos maiores aprimoramentos será o de viver por tanto tempo que poderemos considerar os humanos do futuro imortais, modificando substancialmente o que chamamos de "seres humanos" e "natureza humana".

Voltando, então, ao título de nosso artigo, é muito provável que chegará o dia em que a morte morrerá. Aqui, duas questões emergem. A primeira é uma questão ética no sentido mais geral. A imortalidade seria uma coisa boa e desejável ou não? A segunda questão envolve políticas públicas a curto, médio e longo prazo. Como nos preparar para o dia em que a morte morrerá?

\section{A desejabilidade da imortalidade e a objeção de Hans Jonas à imortalidade}

Vamos focar, inicialmente, na primeira questão, a questão ético/ filosófica por excelência, ou seja, sobre se a imortalidade é algo bom e desejável. John Harris ${ }^{13}$ responde a questão. Ele diz que dado que as pessoas desejam a vida e temem a morte é difícil não ver a longevidade, e talvez a imortalidade, como um bem palpável. Ampliando o argumento em termos de direitos, Harris afirma que proibir a extensão da vida pode ser descrito como uma violação do direito à vida, afirmando que temos não apenas o direito (negativo) à vida, o direito de não sermos mortos, mas também o direito positivo de estender nossas vidas. Para Harris, se salvar

12 SMITH, Robert; SCHROEDER, K-P. "Monthly Notices of the Royal Astronomical", Society, 386 (2008), p. 155-163.

${ }^{13}$ HARRIS, J. Enhancing Evolution. New Jersey: Princeton University Press, 2007, p. 64. 
uma vida é adiar a morte, e adiar a morte nada mais é do que estender a vida, então, salvar uma vida é estendê-la. Entretanto, se estendemos a vida indefinidamente, teríamos a imortalidade.

Parece, no entanto, que o argumento em defesa da imortalidade como sendo um bem só é completo quando consideramos a intensidade do sofrimento humano diante da morte. Os seres humanos são os únicos seres vivos na Terra que têm consciência da sua finitude, como já dizia Heidegger, e isto faz com que sejamos capazes de sofrer diante da perspectiva da morte de um modo muito mais radical do que qualquer outro ser vivo não racional. A radicalidade deste sofrimento deve dar aos homens alguns privilégios se seguirmos a marcha utilitarista que nos diz que a felicidade deve ser maximizada e o sofrimento minimizado. Se Mill tem razão em relação à qualidade dos prazeres, ao dizer que o homem é capaz de prazeres que um porco jamais imaginaria, devemos, por analogia, dizer que o homem é também capaz de sofrimentos que nenhum porco jamais seria capaz de sofrer. Com isto, se justificaria, no caso humano, o direito de estender ao máximo as nossas vidas e mostraríamos que a extensão da vida é desejável.

Há, entretanto, algumas objeções à imortalidade e à extensão da vida, entre elas a de que a imortalidade levaria a superpopulação e ao fim da reprodução, que é a objeção que discutirei aqui. ${ }^{14}$. Este argumento é baseado no fato de que se população humana se tornasse imortal e as pessoas ainda assim continuassem a se reproduzir nas taxas em que os reproduzimos hoje haveria um superpovamento do planeta. A alternativa seria, então, parar de nos reproduzir, para evitar a superpopulação. Hans Jonas, ${ }^{15}$ que alerta sobre o perigo da superpopulação, afirma:

Assim como mortalidade acha sua compensação em natalidade, conversamente a natalidade ganha seu escopo da mortalidade: a morte do velhos abre espaço para os jovens. Esta regra se torna ainda mais forte a medida que nosso números crescem e fazem exceder os limites da tolerância ambiental. O espectro da superpopulação assombra a vida nova, de todo modo; e a proporção de jovens deve encolher em um população forçada a se tornar estática pela sucessivo aumento de sua média de idade

${ }_{14}$ Segundo HARRIS, há precisamente cinco principais tipos de objeções filosóficas ou éticas que têm sido feitas à extensão da vida, são elas: a) a extensão da vida seria injusta, b) seria sem sentido e, em última instância, indesejável por causa do tédio inevitável de uma vida infinita c) seria sem sentido porque a identidade pessoal não poderia sobreviver durante longos períodos de uma existência estendida; posso querer ser imortal, mas ao fim e ao cabo, meu eu futuro não seria "eu" e, então, o projeto falharia d) a extensão da vida seria proibitivamente cara em termos dos custos dos cuidados com a saúde e) Levaria à superpopulação e talvez ao fim da reprodução.

15 JONAS, H. "The burden and blessing of immortality", Hasting Centre Report, 22(1), 1992, p. 34-41. 
através da bem sucedida luta contra a morte prematura. Deveríamos então alargar a vida um pouco mais brincando e batendo o naturalmente ordenado tempo biológico da nossa mortalidade, estreitando ainda mais o espaço dos jovens na nossa sociedade envelhecida? Acredito que o bem comum da humanidade nos faz responder que não...

Parece que Jonas está parcialmente correto em sua análise sobre a necessidade da existência de novos seres humanos e da força criativa destes. Está certo ao afirmar que um mundo onde não se dá a chance de que surjam novos seres humanos seria, acima de tudo, um mundo injusto já que não permitiria que os prazeres e as bênçãos da vida humana sejam conferidos a cada vez mais e mais humanos. O erro de Jonas, entretanto, é o de não considerar a variável do avanço tecnológico em sua análise, não levando em consideração que a imortalidade, se for atingível, só poderia sê-lo através de um longo processo de desenvolvimento tecnológico. A possibilidade de que tenhamos seres humanos vivendo mil anos ainda neste século é mínima e portanto, a afirmação de que a imortalidade necessariamente vai gerar superpopulação e que a superpopulação necessariamente implicará o fim da reprodução não se configura em um problema imediato. O problema poderia ser gerado a longuíssimo prazo, mas pensando também a longuíssimo prazo se for possível tecnologicamente que prolonguemos bastante o tempo de vida dos humanos, haveremos de pensar na hipótese de que também será possível desenvolver uma tecnologia que permitirá que a espécie humana habite, viva e colonize outros planetas que sejam propícios para vida e, se assim for, será possível conciliar a imortalidade com a concepção a medida que continuaremos nos reproduzindo e viajando pelo universo com o objetivo de espalhar a vida e, mais especificamente, a vida inteligente no universo.

\section{Como nos preparar para o dia em que a morte morrerá?}

Mas enquanto tal tempo não chega, a questão que se configura a curto e médio prazo, o problema real a ser enfrentado, embora não seja o da imortalidade versus o fim da reprodução, como pensou Jonas, está ainda relacionado ao problema da superpopulação, na confluência do excessivo número de nascimentos nos países menos desenvolvidos com uma expectativa de vida da população que se torna cada vez maior nos países mais desenvolvidos, e os efeitos devastadores desta combinação no ambiente e na qualidade de vida dos indivíduos.

Quando olhamos para a geografia dos nascimentos, os números impressionam. A população mundial, em 2012, é de um pouco mais de sete bilhões, sendo que quase seis bilhões deste total estão concentrados 
em países menos desenvolvidos. A diferença na taxa de nascimento entre países mais e menos desenvolvidos é espantosa. O número de nascimentos foi de cerca de 140 milhões no ano, sendo que em torno de 14 milhões estiveram concentrados em países mais desenvolvidos e aproximadamente 126 milhões em países menos desenvolvidos, ou seja, os países menos desenvolvidos contribuíram com cerca de 90\% dos nascimentos em 2012. ${ }^{16}$

O fantasma da superpopulação só será afastado através da modificação da nossa mentalidade em relação à reprodução, tornando esta não uma obrigação, mas uma escolha consciente, de modo que nos conscientizemos que o ato de colocar filhos no mundo, o ato de "criar a vida", é um ato que exige responsabilidade e cuidado com o ser gerado. Dar a luz indiscriminadamente e sem responsabilizar-se pela prole, como se o importante fosse a quantidade da geração e não a preocupação com a qualidade de vida, a educação e a formação moral do ser criado, é um comportamento que deveria ceder gradativamente seu lugar à "reprodução consciente", em que o importante não é o número de crianças geradas, mas o cuidado dos pais com elas oferecendo-lhes apoio, carinho, educação e formação moral, e do Estado oferecendo educação para os filhos das famílias carentes, segurança e paz.

Por outro lado, há o desafio de melhorar as condições de vida da terceira idade, de modo que as pessoas possam, cada vez mais, envelhecer mantendo a sua qualidade de vida. Isso implica necessariamente o combate a doenças que atingem, indiscriminadamente, a todas as idades, como o câncer, mas também o combate efetivo às doenças que atingem, prioritariamente, a terceira idade, como as doenças cardiovasculares, doenças do aparelho circulatório, as doenças neurodegenerativas, artrites, osteoporoses, bem como a perda da visão e audição. Ao desenvolvermos tratamentos efetivos para estas doenças, os idosos hão de viver mais e melhor. É preciso, então, que se invista na pesquisa para a cura destas doenças que atingem principalmente aos idosos, ao mesmo tempo em que se estabeleçam políticas que permitam que os idosos continuem ativos, inclusive profissionalmente, se assim o desejarem. $\mathrm{O}$ fim das aposentadorias obrigatórias para quem atinge os 70 anos, assim como o aumento em nível mundial da idade mínima necessária para a

16 POPULATION REFERENCE BUREAU. 2012 world population data sheet. Disponível em: < http://www.prb.org/pdf12/2012-population-data-sheet_eng.pdf>. Os números exatos são os seguintes: A população total do planeta em $\overline{2} 012$ é de 7.057,075,000 sendo $1.243,018,000$ nos países mais desenvolvidos e $5.814,057,000$ nos países menos desenvolvidos. Já em relação ao número de nascimentos tivemos um total anual em 2012 de 140.541,944 sendo 13.923,718 nos países mais desenvolvidos e 126.618,226 nos países menos desenvolvidos. 
aposentadoria, gostemos ou não, parece ser uma tendência mundial irreversível, conjuntamente com a criação de mais e mais oportunidades de trabalho para idosos.

Não há dúvidas de que a questão do estabelecimento de políticas que sejam capazes de lidar com o envelhecimento da população nos países mais desenvolvidos e com as altíssimas taxas de nascimento nos países menos desenvolvidos, gerando um crescimento populacional sem precedentes, será um dos grandes, senão o grande desafio ético e de políticas públicas do século XXI em nível mundial. Apresentei, aqui, uma reflexão e ensaiei algumas propostas, mas ainda há muitas questões em aberto em relação a como lidar com este desafio, e é premente que realizemos um esforço imediato a fim de que as perguntas comecem a ser respondidas e as ações realizadas. O dia em que a morte morrerá pode ainda demorar alguns milhares de anos para chegar, mas é tão grandioso, trata-se de um acontecimento tão transformador, que sua chegada já se anuncia, colocando-nos desafios a serem resolvidos a curto e médio prazo; desafios que, para o bem de todos e a sobrevivência do planeta, é melhor que comecemos a enfrentar ainda hoje.

\section{Referências}

BLACKBURN, Elizabeth; GREIDER, Carol; SZOSTAK, Jack. "The path from maize, Tetrahymena and yeast to human cancer and aging". Nature Medicine, 12(10), 2006, p. vii-xii.

DAWKINS, R. "Gaps in The Mind". In: SINGER, P; CAVALIERI, P. The Great Ape Project. New York: St Martin's Griffin, 1993, p. 81-87

GUILLEBAUD, John; HAYES, P. "Population growth and climate change" (editorial). British Medical Journal BMJ, p. 337-576 doi, (2008).

HARRIS, J. Enhancing Evolution, New Jersey: Princeton University Press, 2007, p. 64. IBGE Estatísticas do Século XX, Rio de Janeiro (2006). Disponível em: < http://www. ibge.gov.br/seculoxx/seculoxx.pdf>.

JONAS, H. "The burden and blessing of immortality". Hasting Centre Report, 22(1), 1992, p. 34-41.

KIRKWOOD, Tom. The End of Age. London: Profile Books, 2001.

KUBOTA, Shin. "Repeating rejuvenation in Turritopsis, an immortal hydrozoan (Cnidaria, Hydrozoa)". Biogeography, 13 (2011), p. 101-103.

OEPPEN, Jim; VAUPEL, James. "Broken Limits to Life Expectancy". Science, 296 (2002), p. 1029-1031.

POPULATION REFERENCE BUREAU 2010 world population data sheet. Disponível em: <http://www.prb.org/Publications/Datasheets/2010/2010wpds>.

POPULATION REFERENCE BUREAU 2012 world population data sheet. Disponível em: <http://www.prb.org/pdf12/2012-population-data-sheet_eng.pdf>. 
C. Nahra - O dia em que a morte morrerá

RILEY, J. Rising Life Expectancy: A Global History. Cambridge: Cambridge Univ. Press, Cambridge, 2001,

SMITH, Robert; SCHROEDER, K. "Monthly Notices of the Royal Astronomical". Society, 386 (2008), p. 155-163.

TEMKIN, Larry. "Is living longer living better?". The Journal of Applied Philosophy, 25(3), 2008, p. 193-210.

Recebido em 14 de janeiro de 2013.

Aprovado para publicação em 31 de fevereiro de 2013. 